\title{
Systemic effects of high dose inhaled steroids: comparison of beclomethasone dipropionate and budesonide in healthy subjects
}

Peter H Brown, Simon P Matusiewicz, Catherine Shearing, Laila Tibi, Andrew P Greening, Graham K Crompton

\begin{abstract}
Background-Systemic absorption of inhaled corticosteroids may adversely influence the function of the hypothalamo-pituitary-adrenal axis, bone metabolism, and circulating leucocytes. These changes can be used to assess the safety of different types and modes of administration of these drugs.

Methods-The study was a randomised, double dummy, crossover design with nine healthy adults. It compared the effects of beclomethasone dipropionate and budesonide (given by metered dose aerosols with and without their respective large volume spacers (Volumatic and Nebuhaler) attached) on serum cortisol, $\mathbf{2 4}$ hour urinary free cortisol, and plasma osteocalcin concentrations, and circulating neutrophils and lymphocytes. Subjects inhaled the drug (1 mg) and matching placebo at 0900 and 2200 hours on each of six study days. Blood samples were taken hourly for six hours after the morning dose and at the end of the study period.

Results-All results were within the reference ranges. Both drugs caused similar reductions in serum cortisol four to six hours after inhalation. These changes were not affected by the use of a large spacer and did not persist at 24 hours. Use of spacers tended to increase the haematological effects of the steroids. Beclomethasone dipropionate inhaled through a Volumatic provoked a rise in circulating neutrophils compared with placebo although lymphocyte numbers were unaffected. Budesonide did not influence neutrophil numbers but did reduce circulating lymphocytes, numbers of which were further reduced when the Nebuhaler was used. There were no significant changes in plasma osteocalcin concentration or 24 hour urinary free cortisol excretion with budesonide, with or without a spacer. Beclomethasone dipropionate inhaled without a spacer reduced urinary cortisol and plasma osteocalcin at 24 hours; however, use of the Volumatic protected against these effects.
\end{abstract}

Conclusions-Attaching a Volumatic reduces the systemic effects of $2 \mathrm{mg}$ aerosol beclomethasone dipropionate on the hypothalamo-pituitary-adrenal axis and circulating osteocalcin concentrations. This study did not establish whether the Nebuhaler reduces the systemic effects of budesonide. When large spacers are used, $2 \mathrm{mg}$ per day of beclomethasone dipropionate and budesonide seem to be equivalent in terms of unwanted effects.

(Thorax 1993;48:967-973)

Systemic absorption of inhaled corticosteroids such as beclomethasone dipropionate or budesonide may influence the activity of the hypothalamo-pituitary-adrenal axis, bone, carbohydrate and lipid metabolism, and circulating leucocytes. ${ }^{1}$ Such changes can be used as markers of unwanted drug effects. It is not clear which of these markers is most sensitive to inhaled corticosteroids, or how changes relate to the risk of major adverse corticosteroid effects such as osteoporosis, myopathy, and cataracts.

In an early study in adult volunteers, ${ }^{2}$ inhaled beclomethasone dipropionate at a dose of $500 \mu \mathrm{g} /$ day caused a rise in circulating neutrophils and a fall in lymphocyte numbers suggesting that a change in peripheral blood leucocytes was a sensitive marker of systemic effects. Tests of hypothalamo-pituitaryadrenal function, usually measurement of morning plasma cortisol concentrations, have long been the standard method of assessing systemic activity. Recently, there has been much interest in indices of bone formation and resorption. Circulating concentrations of osteocalcin, a 49 amino acid protein produced by osteoblasts, seem to correlate well with bone formation. ${ }^{3-5}$ Concentrations show a circadian variation but, by contrast with cortisol, are maximal at night and low around noon. ${ }^{6-8}$ Systemic corticosteroids suppress serum osteocalcin ${ }^{9-11}$ and recent studies show that inhaled corticosteroids may also have this effect. ${ }^{812-17}$

In the treatment of asthma beclomethasone dipropionate and budesonide seem to be equipotent in therapeutic efficacy when similar doses are given. Some studies, however, have reported that when doses $>800 \mu \mathrm{g} /$ day are used, budesonide may have fewer systemic effects. ${ }^{18-22}$ Most of these studies compared the drugs given via the conventional 
metered dose aerosol but current United Kingdom recommendations are that high dose inhaled steroid treatment should be given with a large spacer. ${ }^{23}$ Although there is evidence that hypothalamo-pituitary-adrenal suppression from high doses of beclomethasone dipropionate is reduced by a $750 \mathrm{ml}$ spacer (Volumatic), ${ }^{24-26}$ it has been suggested that the spacer (Nebuhaler) increases the hypothalamo-pituitary-adrenal suppression resulting from budesonide. ${ }^{27}$

This study was designed to compare the short term systemic effects of beclomethasone dipropionate and budesonide given by metered dose aerosols with and without their respective spacers (Volumatic and Nebuhaler).

\section{Methods}

STUDY PROTOCOL

Nine healthy subjects (mean age $32 \cdot 7$ (range 23-56) years, five men) selected from hospital medical and nursing staff participated in the study, which was of randomised double blind double dummy crossover design. None had taken corticosteroids previously. Each was studied on six separate days; the washout period between each study day was a minimum of three days. On two days, subjects inhaled beclomethasone dipropionate from a metered dose aerosol with or without a Volumatic attached, matching placebo being taken by the alternative route. On another two days, budesonide was inhaled with or without a Nebuhaler and matching placebo taken by the other route. Double placebo inhalers were used on the other days. Two double placebo days were necessary as it was impractical to blind investigators and subjects as to which spacer was being used and subjects had to actuate the budesonide canister more often than the beclomethasone dipropionate canister to take the same total dose by weight.

A total daily dose of $2 \mathrm{mg}$ beclomethasone dipropionate or budesonide ( $1 \mathrm{mg}$ in the morning and evening) was chosen as this dose and dosing frequency is widely used and is the maximum recommended. ${ }^{23}$ Canisters of beclomethasone dipropionate dispensed 0.25 mg per puff and subjects therefore used active and placebo inhalers in doses of four puffs twice daily. Canisters of budesonide dispensed $0.2 \mathrm{mg}$ per puff and therefore during the three budesonide study days, subjects took five puffs twice daily from active and placebo inhalers. All subjects were able to use a metered dose aerosol efficiently. When using the spacer, all took two inhalations from the device for each actuation of the aerosol and each inhalation was followed by a breath hold of five seconds. The spacer study medication was inhaled first, immediately followed by conventional aerosol use. Mouths were not rinsed.

On each study day, subjects attended at 0830 and a cannula was sited in a forearm vein. They rested for 30 minutes, after which a venous blood sample $(10 \mathrm{ml})$ was drawn.
Following this, they took study medication, started a 24 hour collection of urine, and continued a normal working day. Further blood samples were drawn at hourly intervals for six hours after which the cannula was removed. The second dose of study medication was taken at 2200 hours and the last blood sample withdrawn at 0900 hours the following day, when the urine collection was completed. The study received ethics committee approval and all subjects gave verbal consent.

ASSAYS

Blood samples were assayed for cortisol and osteocalcin and a differential leucocyte count was taken. Samples for cortisol assay were allowed to clot and the serum was separated and stored at $-20^{\circ} \mathrm{C}$ until analysis. Serum cortisol and the 24 hour urinary excretion of free cortisol were measured by the same commercial radioimmunoassay (Amerlex, Kodak Clinical Diagnostics Ltd, Amersham, UK). The interassay coefficient of variation (CV) was $3 \cdot 7 \%$ at $342 \mathrm{nmol} / 1$ and $3 \cdot 2 \%$ at 760 $\mathrm{nmol} / \mathrm{l}$. In our laboratory, the reference range for 0900 cortisol is $190-550 \mathrm{nmol} / 1$ and for urinary free cortisol excretion $80-450$ nmol/24 hours. Differential leucocyte counts were performed by Coulter counter analysis. The reference range for neutrophil count is $2-7 \cdot 5 \times 10^{9} / 1$ and for lymphocytes $1.5-4$ $\times 10^{9} / 1$. Samples for osteocalcin assay were collected into heparinised containers, centrifuged immediately, and the plasma stored at $-20^{\circ} \mathrm{C}$. Osteocalcin was analysed by an in house radioimmunoassay with an antibody raised in rabbits to purified bovine osteocalcin (intra-assay CV 5\%; interassay CV 12\%; reference range $2-12 \mu \mathrm{g} / \mathrm{l}$ ). Differential leucocyte counts and urine samples were analysed immediately after collection. Blood samples for cortisol and osteocalcin assays were stored until completion of the study and samples from an individual subject (48 in total) were analysed in the same batch.

\section{STATISTICAL ANALYSIS}

Although the study was randomised and double blind with respect to each drug, the differences between the large spacers and the dose per actuation of the aerosols meant that direct comparison between beclomethasone dipropionate and budesonide could not be completely blinded without greatly complicating the study design. The principal comparisons were therefore between each drug and mode of inhalation and their respective placebos. The influence of drug and use of spacer on the various circulating markers during the first six hours after inhalation was assessed by area under the curve analysis with statistical significance determined by paired $t$ tests. These were also used to compare the 24 hour measurements between groups. Bonferroni corrections were used to adjust for multiple comparisons. Changes in 24 hour urinary free cortisol excretion were also analysed with paired $t$ tests. Statistical significance was taken at the $5 \%$ level. 

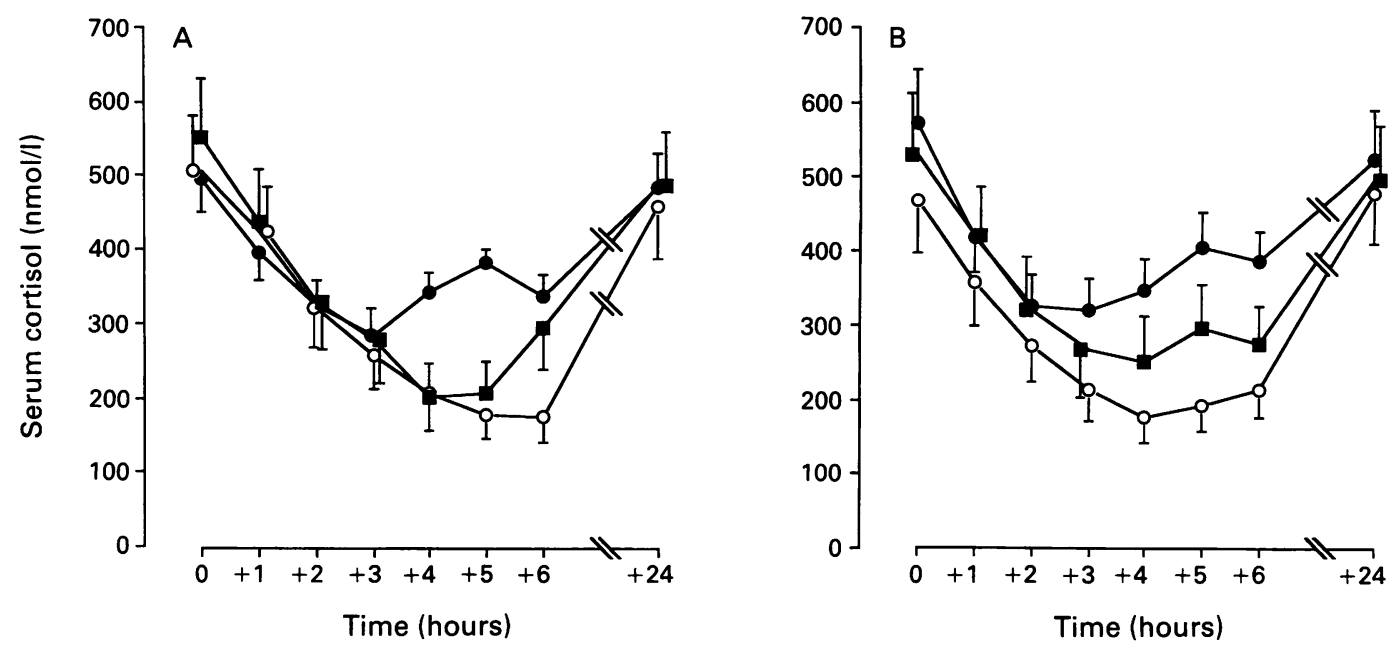

Figure 1 Mean (SE) serum cortisol levels after inhalation of $(A)$ beclomethasone dipropionate or (B) budesonide (1 mg twice daily) with or without a large spacer (O-placebo; $\bigcirc-$ conventional metered dose inhaler; - spacer). Area under the curve from three to six hours is significantly greater $(p<0.05)$ than placebo with both steroids; differences between metered dose inhaler and spacer groups are not significant (see text).

\section{Results}

EFFECTS ON THE HYPOTHALAMO-PITUITARYADRENAL AXIS

Figure 1 shows serum cortisol concentrations after treatment with beclomethasone dipropionate and budesonide. During the first three hours cortisol concentrations were similar to those obtained after placebo but, thereafter, differences between curves for drugs and their placebos were apparent. The area under the curve from zero to six hours did not differ significantly from placebo for both beclomethasone dipropionate and budesonide given without a spacer. As suppressive effects on serum cortisol within the first three hours had not been expected, the area under the curve over the three to six hour time period was

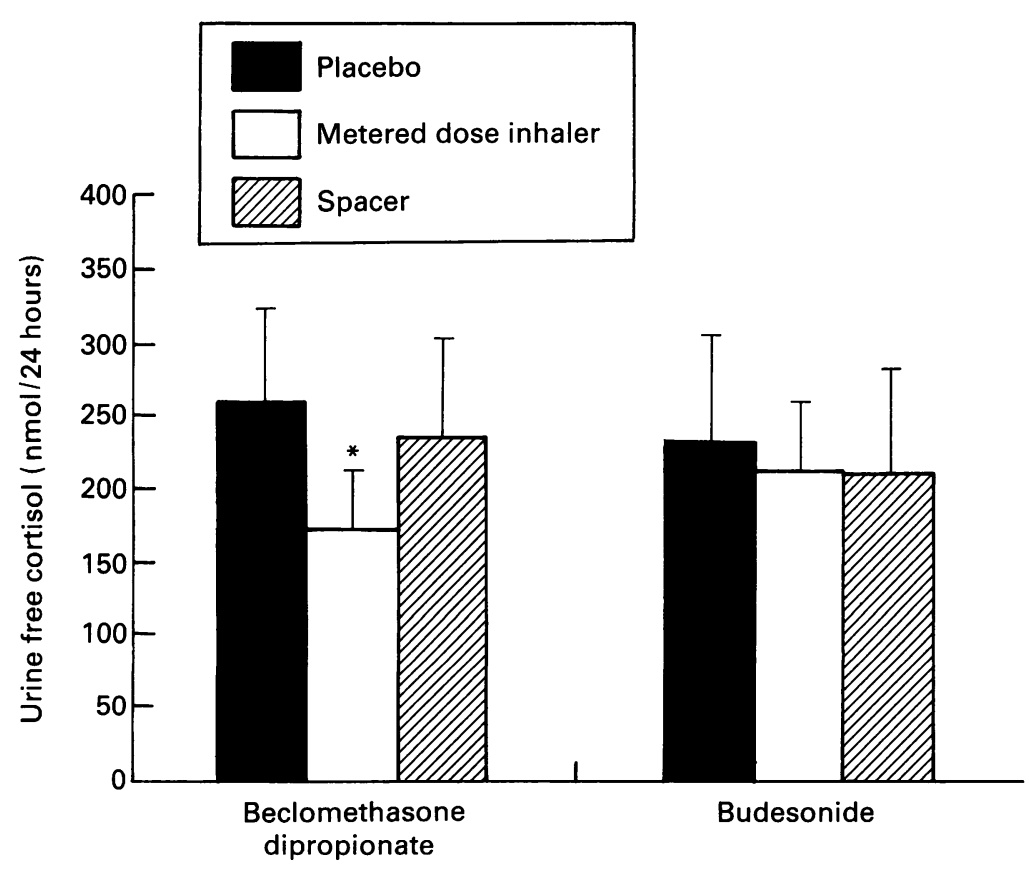

Figure 2 Mean (SD) 24 hour urinary free cortisol excretion after inhalation of beclomethasone dipropionate or budesonide (1 mg twice daily) with or without a large spacer; ${ }^{*} p<0.01 v$ placebo and $p=0.05 v$ spacer. also analysed. During this period the area under the beclomethasone dipropionate curve was greater than placebo whether a Volumatic was used ("spacer" group, p < 0.02 ) or not ("metered dose inhaler" group, $\mathrm{p}<0.05)$. With budesonide the area under the curve was greater when drug was taken through the Nebuhaler $(\mathrm{p}<0.05 v$ placebo); without the spacer the difference approached significance $(p=0.06)$. With both drugs, the area under the curve without a spacer was similar to when the spacer was used. Neither steroid influenced the 0900 cortisol 24 hours after the initial $1 \mathrm{mg}$ dose ( 11 hours after the second dose).

Figure 2 shows the results of 24 hour urinary free cortisol excretion. Excretion was reduced when beclomethasone dipropionate was inhaled without a spacer (mean 172 nmol/24 hours) when compared with placebo (mean $256 \mathrm{nmol} / 24$ hours; $\mathrm{p}<0.01$ ) but was similar to placebo values when the Volumatic (mean $233 \mathrm{nmol} / 24$ hours) was used. When budesonide was inhaled, urinary cortisol was similar with (212 nmol/24 hours) or without (213 nmol/24 hours) a Nebuhaler and not significantly different from placebo (234 nmol/24 hours). The difference between beclomethasone dipropionate and budesonide inhaled without a spacer was not significant.

EFFECTS ON CIRCULATING LEUCOCYTES

Figure 3 shows the changes in peripheral blood neutrophil and lymphocyte counts. During the first six hours after beclomethasone dipropionate, the area under the lymphocyte curves was similar to placebo but the area under the curve for neutrophils was greater when a Volumatic was used $(p<0.02$ $v$ placebo). The area under the curve when beclomethasone dipropionate was inhaled without a spacer was intermediate between placebo and spacer curves and not significantly different from either. Results at 24 hours were also not significantly different between groups. By contrast, the effects of 

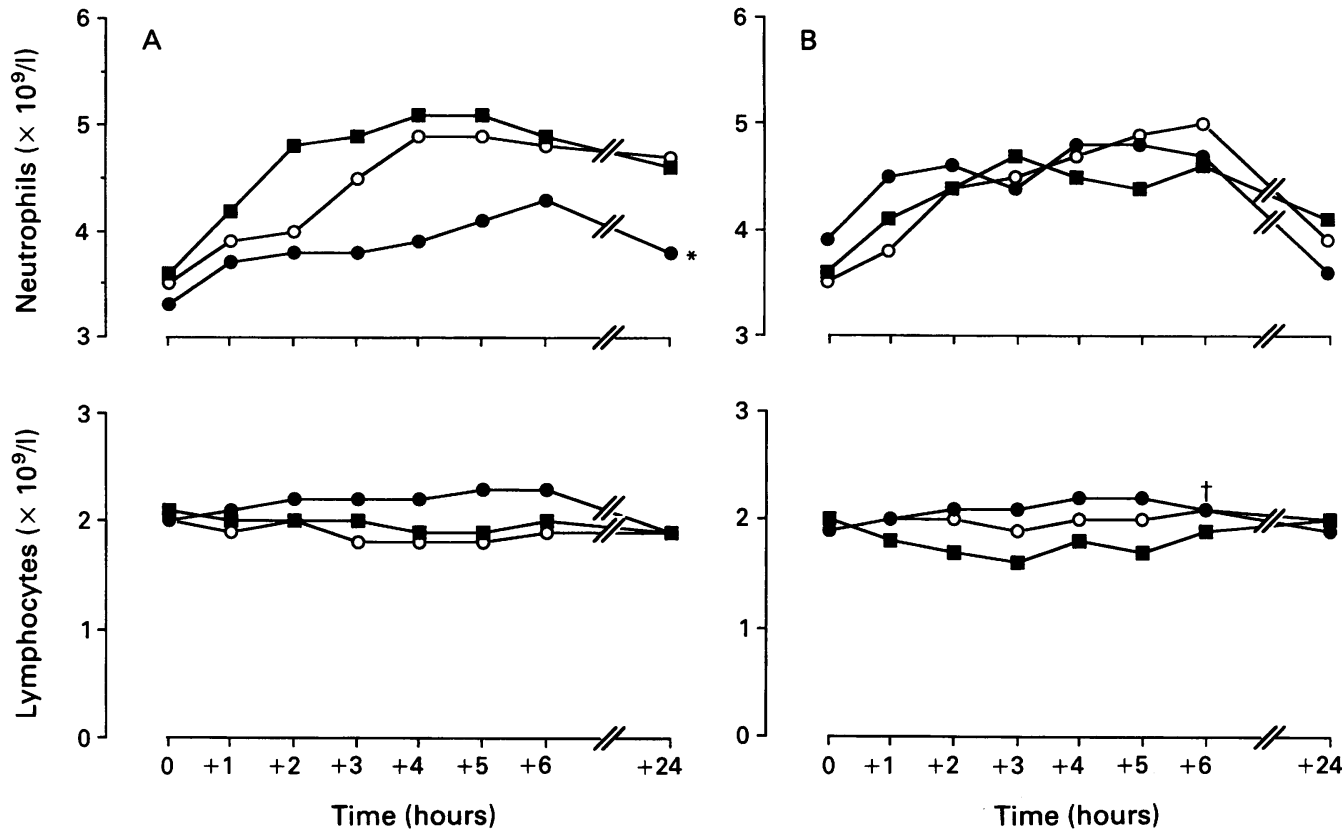

Figure 3 Mean plasma neutrophil and lymphocyte numbers after inhalation of $(A)$ beclomethasone dipropionate or $(B)$ budesonide with or without a large spacer (O-placebo; $\mathrm{O}-$ metered dose inhaler (MDI); - spacer). For beclomethasone dipropionate $\left({ }^{\star}\right)$, area under the neutrophil curve from zero to six hours for spacer use is significantly greater than placebo $(p<0.02)$. For budesonide $(\dagger)$, areas under the lymphocyte curves differ significantly for spacer $v$ metered dose inhaler and placebo (both $p<0.01$ ) and metered dose inhaler v placebo $(p<0.05)$ (see text).

budesonide on neutrophils were similar to placebo but the area under the lymphocyte curve was reduced when the drug was inhaled in conventional fashion (metered dose inhaler, $p=0.05$ ) and further reduced when the Nebuhaler was used ( $\mathrm{p}<0.01 v$ metered dose inhaler and placebo). There were no differences at 24 hours. In a direct comparison of beclomethasone dipropionate and budesonide, the area under the neutrophil curve was greater with beclomethasone dipropionate via the Volumatic than with budesonide via the Nebuhaler $(p<0.05)$; however, there was a trend towards a difference between the corresponding placebo curves.

EFFECTS ON OSTEOCALCIN

Figure 4 shows plasma osteocalcin concentrations. There was considerable variation between subjects and this is reflected in the wide standard error bars. No significant changes were observed with either drug during the first six hours. When beclomethasone dipropionate was inhaled without a spacer, plasma osteocalcin at 24 hours was significantly lower than when placebo was given
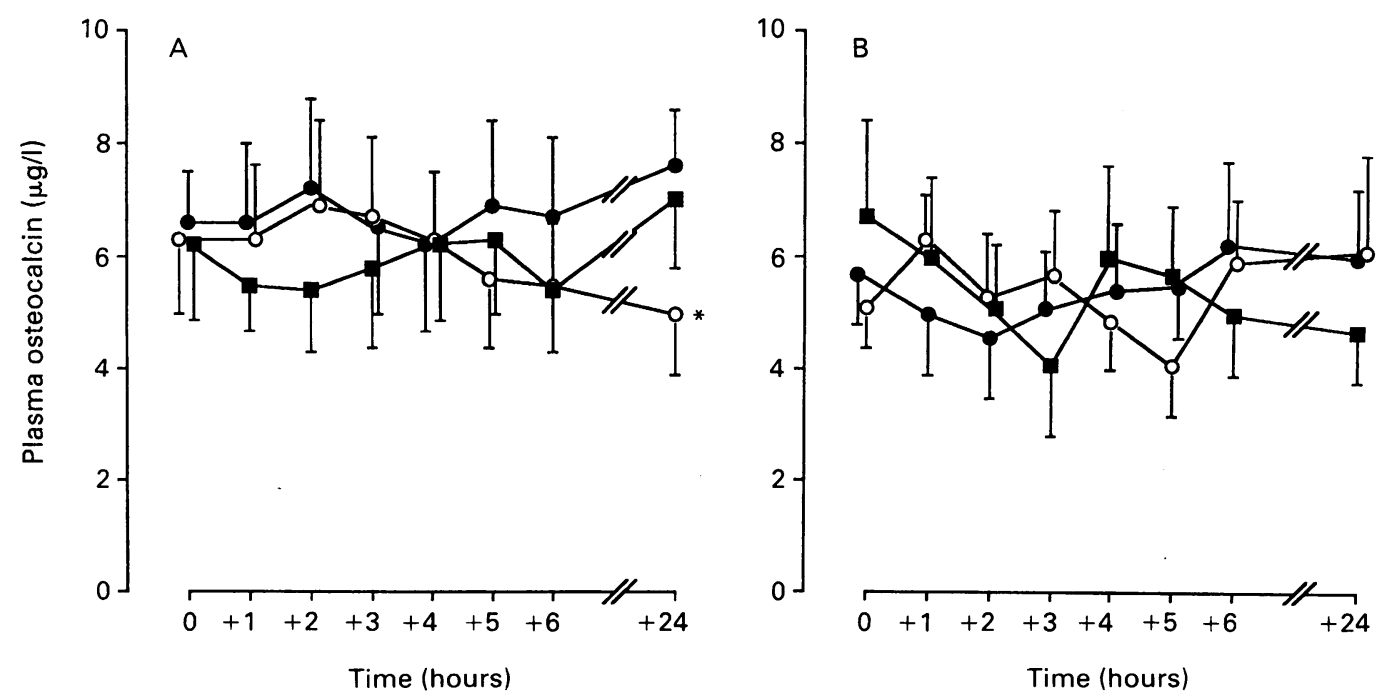

Figure 4 Mean (SE) plasma osteocalcin levels after inhalation of $(A)$ beclomethasone dipropionate or (B) budesonide (1 mg twice daily) with or without a large spacer ( - placebo; $O$-metered dose inhaler; $\square-$ spacer); ${ }^{\star} p<0.01 v$ spacer and placebo. 
$(\mathrm{p}<0.01)$ or the spacer was used $(\mathrm{p}<0.02)$. By contrast budesonide did not influence 24 hours osteocalcin. In a direct comparison, the effect of beclomethasone dipropionate was not significantly different from that of budesonide.

\section{Discussion}

With increasing use of high dose inhaled corticosteroid treatment, there is a need to establish whether similar doses of beclomethasone dipropionate and budesonide have clinically important differences in unwanted systemic effects. This study compared the short term influences of these drugs, administered by metered dose aerosol, on the adrenal axis, plasma osteocalcin concentrations, and circulating leucocytes. After inhalation of $1 \mathrm{mg}$ of each drug at 0900 hours, similar suppressive effects on serum cortisol concentrations were observed after four to six hours although results were still within normal limits. Attaching a large spacer did not significantly influence the degree of suppression during this period although examination of the curves for beclomethasone dipropionate (fig 1) suggested that serum cortisol concentrations were recovering at six hours when the drug was taken through a spacer but not when taken in conventional fashion. Unfortunately serum cortisol was not measured between six and 12 hours to establish whether this possible protective effect was sustained. When the effects of the total dose of $2 \mathrm{mg}$ on the hypothalamo-pituitary-adrenal axis were assessed by 24 hour urinary free cortisol determination, excretion was only maintained when a Volumatic was used. This is consistent with a protective effect of this spacer on suppression of the hypothalamopituitary-adrenal axis as shown in earlier studies. $^{24-26}$ The $2 \mathrm{mg}$ total dose of budesonide did not significantly reduce urinary cortisol whether or not a Nebuhaler was used.

The spacer was also shown to protect against the effects of beclomethasone dipropionate on circulating osteocalcin. At the end of the 24 hour study period, plasma osteocalcin concentrations were significantly lower after beclomethasone dipropionate inhaled without the spacer than when the Volumatic was used. Budesonide with or without the Nebuhaler did not significantly affect plasma osteocalcin concentrations. When compared with placebo, there were also differences between the systemic effects of beclomethasone dipropionate and budesonide on circulating neutrophils and lymphocytes. Neutrophil counts rose after inhalation of either placebo, possibly due to the presence of an indwelling cannula although an effect from aerosol propellants could not be excluded. When compared with placebo, neutrophil numbers were significantly higher after beclomethasone dipropionate was inhaled through a Volumatic. There was no evidence for a protective effect from the spacer for this marker of systemic effect. Budesonide did not influence neutrophils but slightly reduced circulating lymphocytes, an effect that was significantly more pronounced when the Nebuhaler was used.

The difference in appearance of the large spacers and the greater number of puffs of trial medication on budesonide study days meant that direct comparison of beclomethasone dipropionate with budesonide for any marker of systemic effect was not completely blinded. When beclomethasone dipropionate and budesonide were directly compared with or without spacers, however, there were no significant differences for any marker of systemic effect (apart from neutrophil numbers when analysis may have been confounded by a trend towards a difference between placebo curves). We cannot exclude the possibility that differences would have been found if a larger number of subjects had been studied or chronic dosing used.

The systemic effects of high doses of beclomethasone dipropionate and budesonide have been compared in at least seven studies. In a double blind study, Johansson et al ${ }^{18}$ measured plasma cortisol and peripheral white cell counts in 12 healthy adults at 0800,1000 , and 1200 hours, after single doses of $0.4,0.8$, and $3.2 \mathrm{mg}$ of beclomethasone dipropionate or budesonide had been taken at 2200 hours the night before. Area under the curve analysis of the limited number of plasma cortisol data points showed greater suppression caused by beclomethasone dipropionate at the highest dose. In an open study, Lofdahl ${ }^{19}$ selected 12 healthy adults who showed pronounced reductions in serum cortisol in response to $4.5 \mathrm{mg}$ beclomethasone dipropionate a day for two days. In these subjects, $1.5 \mathrm{mg}$ beclomethasone dipropionate and $2.4 \mathrm{mg}$ budesonide, both given for two days, caused similar reductions $(20 \%)$ in morning serum cortisol concentrations. The increases in cortisol suppression when these doses were doubled and trebled were also similar, suggesting that if the same doses were given, budesonide would have less systemic effect than beclomethasone dipropionate. Pedersen ${ }^{20}$ reported an open crossover study in which asthmatic children (some using spacers) were treated with beclomethasone dipropionate or budesonide $(0 \cdot 8-1 \cdot 2 \mathrm{mg} /$ day $)$, each treatment period lasting six weeks. Twenty four hour urinary free cortisol excretion was significantly higher during budesonide treatment. No effect of the spacer was seen. In a double blind study of asthmatic adults, Ebden $e t a^{28}$ found similar reductions in morning plasma cortisol resulting from treatment with $1.5 \mathrm{mg}$ beclomethasone dipropionate and $1.6 \mathrm{mg}$ budesonide (given by a small collapsible spacer), each for six weeks. Jennings ${ }^{21}$ compared the drugs at doses of 0.8 and 2.5 $\mathrm{mg} /$ day in an open study of healthy subjects. Dose related suppression of adrenal function and serum osteocalcin was seen with both drugs and effects were significantly greater with beclomethasone dipropionate. Two studies have compared the drugs given by large spacer. Ali et $a^{22}$ measured indices of 
bone resorption (urine hydroxyproline/creatinine ratio) and formation (serum alkaline phosphatase) in healthy men and found that these were adversely influenced by beclomethasone dipropionate $(2 \mathrm{mg} /$ day $)$ but not by budesonide $(1.8 \mathrm{mg} /$ day $)$. The drugs were not compared at the same dose and the number of data points used in the area under the curve analysis was small. Prahl gave both drugs via a Nebuhaler in an open study ${ }^{29}$ and found interindividual differences in degree of suppression of urinary cortisol in some children but no difference between beclomethasone dipropionate and budesonide.

This study provides further evidence that when high dose inhaled corticosteriods are given by metered dose aerosol without a large spacer attached, the systemic effects with beclomethasone dipropionate are greater than with budesonide. The magnitude of changes in serum and urinary cortisol and plasma osteocalcin concentrations and circulating neutrophils was small with results remaining within reference ranges. This study did not examine the effects of chronic dosing but if long term treatment of asthmatic patients caused changes of similar magnitude, it is unlikely that these would be clinically important. Also evident is the relative insensitivity of 0900 serum cortisol concentration as a screening test for the systemic effects of inhaled steroids. Changes in serum cortisol profile, 0900 plasma osteocalcin and 24 hour urinary free cortisol were not accompanied by any change in 0900 serum cortisol. Studies that do not find any differences in the systemic effects of different doses or types of inhaled corticosteroid should be interpreted with caution if the sole marker of systemic effect is the morning cortisol concentration.

The relation between effects of steroids on indices of hypothalamo-pituitary-adrenal function and bone metabolism and clinically important adverse effects such as osteoporosis, cataracts, myopathy, and risk of adrenal crisis, is still unclear. We have not found evidence of a reduced cortisol stress response to acute asthma in patients taking high dose inhaled steroids ${ }^{30}$ and have suggested that identifying hypothalamo-pituitary-adrenal axis suppression may be useful in predicting which patients are more likely to suffer adverse effects on connective tissue. ${ }^{31} 32$ Proof is lacking that the frequency of these effects is increased if subnormal hypothalamo-pituitary-adrenal axis function is present. There is considerable concern that long term use of high dose inhaled steroids might cause osteoporosis but if systemic absorption of an inhaled steroid causes only minor reduction in endogenous steroid production, it is unlikely that the net result will be increased steroid effects on bone. The value of markers of bone metabolism such as circulating osteocalcin has yet to be established: a recent cross sectional study did not find reduced concentrations in asthmatic patients with reduced bone density. ${ }^{33}$ Longitudinal studies of bone density with parallel measurements of hypothalamo-pituitary-adrenal function and bone biochemistry should determine which test is most useful in predicting a high risk of osteoporosis; such studies have yet to be reported.

This study found that the Volumatic protects against systemic effects of high dose aerosol beclomethasone dipropionate on the hypothalamo-pituitary-adrenal axis and also provides some evidence of protection against bone effects. We did not establish whether the Nebuhaler affords similar protection against the systemic effects of budesonide. We studied healthy subjects and it may be argued that systemic absorption of an inhaled steroid might be increased across an inflamed asthmatic airway. Reports of a similar beneficial effect from spacer use in adults ${ }^{24}{ }^{26}$ and children ${ }^{34}$ with asthma suggest that this does not occur. When large spacers are used, currently recommended maximum doses of beclomethasone dipropionate and budesonide seem to have equivalent systemic effects.

We thank Dr Mike Mackie and the staff of the haematology laboratory, Western General Hospital, for performing the differential leucocyte counts and $\mathrm{Dr}$ Gillian Blundell, Department of Clinical Chemistry, Western General Hospital, for her support. We also thank Dorothy McArthur for treatment coding, Dr Rob Elton, University of Edinburgh, for advice regarding statistical analysis, and our colleagues (CS $\mathrm{FB}, \mathrm{KL}, \mathrm{CMcM}, \mathrm{CA}$ ) for their enthusiastic participation.

1 Geddes DM. Inhaled corticosteroids: benefits and risks. Thorax 1992;47:404-7.

2 Harris DM. Clinical pharmacology of beclomethasone dipropionate. In Mygind N, Clark TJH, eds. Topical steroid treatment for asthma and rhinitis. London: Bailliere Tindall, 1980:34-47.

3 Brown JP, Delmas PD, Malaval L, Edouard C, Chapuy MC, Meunier PJ. Serum bone Gla-protein: a specific marker for bone formation in postmenopausal osteoporosis. Lancet 1984;i:1091-3.

4 Delmas PD, Malaval L, Arlot ME, Meunier PJ. Serum bone Gla-protein compared to bone histomorphometry in endocrine disease. Bone 1985;6:339-41.

5 Garcia-Carrasco M, Grason M, Vernejoul MC de, Denne MA, Miravet L. Osteocalcin and bone histomorphometric parameters in adults without bone disease. Calcif Tissue Int 1988;42:13-7.

6 Gundberg CM, Markowitz ME, Mizruchi M, Rosen JF. Osteocalcin in human serum: a circadian rhythm. $f$ Clin Endocrinol Metab 1985;60:736-9.

7 Nielsen HK, Laurberg P, Brixen K, Mosekilde L. Relations between diurnal variations in serum osteocalcin, cortisol, parathyroid hormone and ionised calcium in normal individuals. Acta Endocrinol 1991;124:391-8.

8 Pouw EM, Prummel MF, Oosting H, Roos CM, Endert E. Beclomethasone inhalation decreases serum osteocalcin concentrations. BMF 1991;302:627-8.

9 Reid IR, Chapman GE, Fraser TRC, Davies AD, Surus AS, Meyer J, Huq NL, Ibbertson HK. Low serum osteocalcin levels in glucocorticoid-treated asthmatics. osteocalcin levels in glucocorticoid-treat.

10 Peretz A, Praet J-P, Bosson D, Rozenberg S, Bourdoux P. Serum osteocalcin in the assessment of corticosteroidinduced osteoporosis. Effect of long and short term corticosteroid treatment. $\mathcal{F}$ Rheumatol 1989;16:363-7.

11 Prummel MF, Wiersinga WM, Lips P, Sanders GTB, Sauerwein HP. The course of biochemical parameters of bone turnover during treatment with corticosteroids. f Clin Endocrinol Metab 1991;72:382-5.

12 Jennings BH, Andersson K-E, Johansson SA. Assessment of systemic effects of inhaled glucocorticosteroids: comparison of the effects of inhaled budesonide and oral turnover. Eur $₹$ Clin Pharmacol 1991;40:77-82.

13 Toogood JH, Jennings B, Hodsman AB, Baskerville J, Fraher LJ. Effects of dose and dosing schedule of inhaled budesonide on bone turnover. $\mathcal{F}$ Allergy Clin Immunol 1991;88:572-80.

14 Hodsman AB, Toogood JH, Jennings $B$, Fraher $L J$ Baskerville JC. Differential effects of inhaled budesonide and oral prednisolone on serum osteocalcin. 7 Clin Endocrinol Metab 1991;72:530-40.

15 Teelucksingh S, Padfield PL, Tibi L, Gough KJ, Holt PR. 
Inhaled corticosteroids, bone formation and osteocalcin. Lancet 1991;338:60-1.

16 Meeran K, Hattersley A, Burrin J, Shiner R, Ibbertson K. Oral and inhaled corticosteroids suppress bone formation (abstract). Am Rev Respir Dis 1991;143:A625.

17 Puolijoki H, Liipo J, Herrala J, Salmi J, Risteli J, Tala R. Does high dose inhaled beclomethasone affect calcium metabolism? (abstract) Eur Respir f 1991;4(suppl 14): 483S.

18 Johansson SA, Andersson K-E, Brattsand R, Gruvstad E, Hedner P. Topical and systemic glucocorticoid potencies of budesonide and beclomethasone dipropionate in man. Eur f Clin Pharmacol 1982;22:523-9.

19 Lofdahl C-G, Mellstrand T, Svedmyr N. Glucocorticoids and asthma. Studies of resistance and systemic effects of glucocorticoids. Eur $\mathcal{f}$ Respir Dis 1984;65(suppl 136): 69-77.

20 Pedersen S, Fuglsang G. Urine cortisol excretion in children treated with high doses of inhaled corticosteroids: a comparison of budesonide and beclomethasone. Eur Respir f 1988;1:433-5.

21 Jennings BH, Larsson B, Andersson K-E, Johansson S-A. The assessment of systemic effects of inhaled glucoThe assessment of systemic effects of inhaled gluco-
corticosteroids: a comparison of budesonide and beclomethasone dipropionate in healthy volunteers. In Jennings BH. Assessment of systemic effects of inhaled glucocorticosteroids. Thesis, University of Lund, 1990.

22 Ali NJ, Capewell S, Ward MJ. Bone turnover during high dose inhaled corticosteroid treatment. Thorax 1991;46: 160-4.

23 British Thoracic Society, Research Unit of the Royal College of Physicians of London, Kings Fund Centre, National Asthma Campaign. Guidelines for management of asthma in adults: I-chronic persistent asthma. BMF 1990;301:651-3.

24 Brown PH, Blundell G, Greening AP, Crompton GK. Do large volume spacer devices reduce the systemic effects of high dose inhaled corticosteroids? Thorax 1990; 45:736-9.
25 Farrer M, Francis AS, Pearce SJ. Morning serum cortisol concentrations after $2 \mathrm{mg}$ inhaled beclomethasone dipropionate in normal subjects: effect of a $750 \mathrm{~m}$ spacer device. Thorax 1990;45:740-2.

26 Selroos $O$, Halme $M$. Effect of a volumatic spacer and mouth rinsing on systemic absorption of inhaled corticosteroids from a metered dose inhaler and dry powder inhaler. Thorax 1991;46:891-4

27 Toogood $\mathrm{JH}$, Baskerville $\mathrm{J}$, Jennings $\mathrm{B}$, Lefcoe $\mathrm{N}$, Johansson S-A. Use of spacers to facilitate inhaled corticosteroid treatment of asthma. Am Rev Respir Dis 1984; 129:723-9.

28 Ebden P, Jenkins A, Houston G, Davies BH. Comparison of two high dose corticosteroid aerosol treatments beclomethasone dipropionate $(1500 \mu \mathrm{g} /$ day $)$ and budesonide $(1600 \mu \mathrm{g} /$ day), for chronic asthma. Thorax 1986; 41:869-74.

29 Prahl P. Adrenocortical suppression following treatment with beclomethasone and budesonide. Clin Allergy 1991;21:145-6.

30 Brown PH, Blundell G, Greening AP, Crompton GK High dose inhaled corticosteroids and the cortisol stress response to acute severe asthma. Respiratory Medicine 1992;86:495-7.

31 Brown PH, Blundell G, Greening AP, Crompton GK Screening for hypothalamo-pituitary-adrenal axis suppression in asthmatics taking high dose inhaled corticosteroids. Respiratory Medicine 1991;85:511-6.

32 Brown PH, Greening AP, Crompton GK. Large volume spacer devices and the influence of high dose spacer devices and the influence of high dose
beclomethasone dipropionate on hypothalamo-pituitaryadrenal suppression. Thorax 1993;48:233-8.

33 Packe GE, Douglas JG, McDonald AF, Robins SP, Reid DM. Bone density in asthmatic patients taking high dose inhaled beclomethasone dipropionate and intermittent systemic corticosteroids. Thorax 1992;47:414-7.

34 Prahl P, Jensen T. Decreased adreno-cortical suppression utilizing the Nebuhaler for inhalation of steroid aerosols. Clin Allergy 1987;17:393-8. 